EPJ Web of Conferences 56, 02003 (2013)

DOI: $10.1051 /$ epjconf/20135602003

(C) Owned by the authors, published by EDP Sciences, 2013

\title{
Effect of blastfurnace slag addition to Portland cement for cationic exchange resins encapsulation
}

\author{
E. Lafond ${ }^{1, \mathrm{a}}$, C. Cau Dit Coumes ${ }^{1}$, S. Gauffinet ${ }^{3}$, D. Chartier ${ }^{1}$, P. Le Bescop ${ }^{2}$, L. Stefan ${ }^{4}$, A. Nonat ${ }^{3}$ \\ ${ }^{1}$ Commissariat à l'Energie Atomique et aux Energies Alternatives, CEA/DEN/MAR/DTCD/SPDE, \\ BP17171, 30207 Bagnols-sur-Cèze cedex, France \\ ${ }^{2}$ Commissariat à l'Energie Atomique et aux Energies Alternatives, CEA/DEN/ SAC/DPC/SECR, \\ 91192 Gif/Yvette, France \\ ${ }^{3}$ ICB, UMR 5209 CNRS Université de Bourgogne, 21078 Dijon, France \\ ${ }^{4}$ AREVA NC / BU-Valorisation, 1 place Jean Millier 92084 Paris La Défense, France
}

\begin{abstract}
In the nuclear industry, cement-based materials are extensively used to encapsulate spent ion exchange resins (IERs) before their final disposal in a repository. It is well known that the cement has to be carefully selected to prevent any deleterious expansion of the solidified waste form, but the reasons for this possible expansion are not clearly established. This work aims at filling the gap. The swelling pressure of IERs is first investigated as a function of ions exchange and ionic strength. It is shown that pressures of a few tenths of MPa can be produced by decreases in the ionic strength of the bulk solution, or by ion exchanges $\left(2 \mathrm{Na}^{+}\right.$instead of $\mathrm{Ca}^{2+}, \mathrm{Na}^{+}$instead of $\left.\mathrm{K}^{+}\right)$. Then, the chemical evolution of cationic resins initially in the $\mathrm{Na}^{+}$form is characterized in CEM I (Portland cement) and CEM III (Portland cement + blastfurnace slag) cements at early age and an explanation is proposed for the better stability of CEM III material.
\end{abstract}

\section{Introduction}

Ion exchange resins, noted IERs, are widely used worldwide by the nuclear industry to decontaminate radioactive effluents. These resins are low level or intermediate level radioactive wastes and have to be stabilized and solidified, i.e. placed under a solid, stable, monolithic and confining form before their final disposal in a repository. Calcium silicate cements offer many advantages for resins encapsulation: easy supply, simple process, good mechanical strength, compatibility with aqueous wastes, good self-shielding, and high alkalinity which allows precipitating and thus confining many radionuclides [1-6]. However, several specificities of IERs must be taken into account to design a robust formula for the final product.

(i) The IERs can exchange ions with the cementitious medium, which may influence cement hydration. For instance, Morin et al. [7] have shown that an addition of a finely-ground ion-IERS in the $\mathrm{Na}^{+}$form makes it possible to accelerate the hydration of $\mathrm{C}_{3} \mathrm{~S}$. Two processes would be involved.

\footnotetext{
a emilie.lafond@cea.fr
} 
The IERS very rapidly exchange sodium ions for calcium ions during the early stage of hydration, which increases the silica concentration in solution and thus the quantity of initially precipitated C$\mathrm{S}-\mathrm{H}$ nuclei. The surface of the resins also provides sites for the nucleation and growth of $\mathrm{C}-\mathrm{S}-\mathrm{H}$ hydrates and/or portlandite far away from the surface of the $\mathrm{C}_{3} \mathrm{~S}$ grains. This consequently increases the quantity of hydrates that can precipitate before the formation of a continuous hydrate layer over the surfaces of $\mathrm{C}_{3} \mathrm{~S}$ particles. On the contrary, cement-based materials containing IERs in the borate form usually exhibit very long setting times. The borate ions initially fixed on the resins readily exchange with hydroxide and sulphate ions released by the dissolution of anhydrous cement phases and retard cement hydration [8].

(ii) IERs are highly porous materials with very poor mechanical strength. The higher their incorporation rate in a cementitious matrix, the lower the strength of the resulting material [9].

(iii) In aqueous medium, it is well known that the volume of IERs beads strongly depends on the composition of the solution [10]. Expansion or shrinkage can be caused by ionic exchanges and/or osmotic pressure due to concentration gradients. These volume changes can also occur in a cementitious matrix, the chemistry of which evolves with ongoing hydration. Under severe conditions (wet curing, high IERs incorporation rate), they can induce cracking of the matrix.

In the literature, knowledge about the chemical evolution of ion exchange resins in cement environment is incomplete [11]. For example, it is often mentioned that the cementation of IERs with ordinary Portland cement (OPC) leads to strong expansion during the early stages of cement hydration, while no swelling is observed when OPC is blended with high amounts of blastfurnace slag [11-14]. However, the reasons for these different behaviours are not understood. A clear depiction of the chemical evolution of ion exchange resins with ongoing cement hydration and its influence on the properties of the matrix is required to assess the durability of the solidified waste forms.

The first objective of this work is to investigate the influence of two main parameters responsible for the volume change of IERs: nature of the ions fixed on the functional groups, and ionic strength of the aqueous solution percolated through the resin.

The second objective is to explain why cements containing high amounts of blastfurnace slag are more appropriate than OPC to solidify cationic IERs saturated with sodium.

\section{Experimental}

\subsection{Materials involved}

\subsubsection{Ion exchange resins}

The IERs considered in this paper were constituted by a polystyrenic backbone, reticulated with divinylbenzene, and functionalized with sulfonic groups. They were supplied by Rohm\&Haas under the trade name Amberlite IR120H. Their physical and chemical properties are presented in Table 1. Three different and frequently encountered forms of cationic resins were studied: $\mathrm{Na}^{+}, \mathrm{K}^{+}$, and $\mathrm{Ca}^{2+}$. The sorption sites of the commercial resins initially, in the $\mathrm{H}^{+}$form were saturated with $\mathrm{Na}^{+}, \mathrm{K}^{+}$and $\mathrm{Ca}^{2+}$ by percolation of solutions of $\mathrm{NaOH}, \mathrm{KOH}$ and $\mathrm{Ca}(\mathrm{OH})_{2}$. The $\mathrm{pH}$ of the solution eluted from the resins was continuously monitored, and the percolation was stopped as soon as the $\mathrm{pH}$ exceeded 7. Then, the resins were rinsed with water to eliminate the excess of base and to recover a neutral $\mathrm{pH}$. 
Table 1. Physical and chemical properties of commercial IERs.

\begin{tabular}{|c|c|}
\hline Name & Amberlite IR120H \\
\hline Classification & Cationic strong acid \\
\hline Functional group & Sulfonic \\
\hline Backbone & Polystyrenic gel \\
\hline Granule size $\left(\mathrm{d}_{50}\right)$ & $100 \mu \mathrm{m}$ \\
\hline Density & 1.09 \\
\hline Exchange capacity (eq/kg dry resins) & 4.8 \\
\hline Reticulation degree $(\% \mathrm{DVB})$ & 8 \\
\hline
\end{tabular}

\subsubsection{Cements}

The first cement used in this study was a CEM III/C. According to European standard EN 1971:2000, this cement corresponds to a Blast Furnace Cement consisting of 5-19\% Portland Cement Clinker and $81-95 \%$ blast furnace slag. The second cement was a CEM I. According to European standards EN 197-1:2000, this type of cement comprises 95-100\% Portland Cement Clinker.

\subsection{Process to measure swelling pressures}

A method was developed to measure the swelling pressure induced by resins under constrained environment. This method is based on some experiments performed by Matsuda in 1992 [11]. Figure 1 shows a schematic of the experimental device. $150 \mathrm{~g}$ of humid ion exchange resins (which corresponds to about $75 \mathrm{~g}$ dry resin) in different forms were introduced in a cylindrical cell (120 mm in diameter) containing a metallic fritted disc at the bottom. A pressure of $10 \mathrm{MPa}$ was applied with a press and enabled to get a $8 \mathrm{~mm}$ high pellet. The pressure value resulted from a compromise to avoid damaging the IERs while getting a handleable pellet. The pressure was then removed. A second fritted disc was placed on the upper surface of the IERs pellet and the cell was tightly closed with a piston connected to a strength gauge. The device also comprised a displacement gauge, placed on the top of the piston (Figure 1) to check the rigidity of the cell (absence of deformation during the experiments). A fluid circulation could be established in the cell through capillaries in the bottom and top of the cell. An initial pressure of $1.8 \mathrm{MPa}$ was applied for each trial. Then, after pressure stabilization, different solutions were percolated through the resins and the pressure variations were monitored via the strength gauge connected to a data logger. The initial loading of the sample made it possible to detect pressure decrease due to shrinkage of the resin grains, or pressure increase due to swelling of the resin grains.

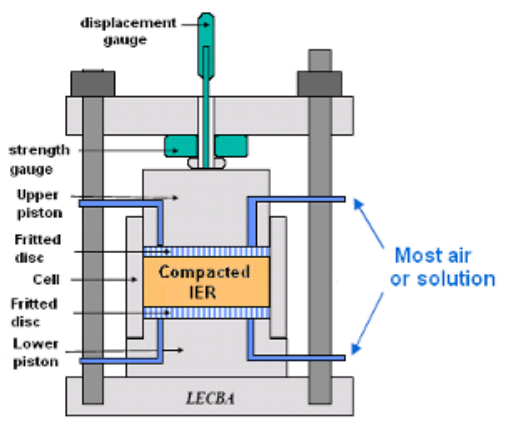

Fig. 1. Experimental device to measure swelling pressure induced by IERs under constrained environment.

To clarify the influence of different parameters on the volume changes of IERs, several tests were performed.

First, the influence of the ionic strength of the percolating solution was investigated at constant ionic form of the IERs $\left(\mathrm{Na}^{+}, \mathrm{K}^{+}, \mathrm{Ca}^{2+}\right)$. Water was first percolated through the cell, and replaced by a relevant diluted nitrate solution $\left(\mathrm{NaNO}_{3}\right.$ solution for $\mathrm{Na}^{+}$-IERs, $\mathrm{KNO}_{3}$ solution for $\mathrm{K}^{+}$-IERs, and 
$\mathrm{Ca}\left(\mathrm{NO}_{3}\right)_{2}$ for $\mathrm{Ca}^{2+}$-IERs). The concentration was then increased step by step, and the pressure was measured once equilibrium was reached for each investigated concentration.

Then, the influence of ionic exchange was investigated: the resins were initially in the $\mathrm{Na}^{+}$form and equilibrated with a $\mathrm{NaNO}_{3}$ solution. This solution was successively replaced by a $\mathrm{KNO}_{3}$ solution to investigate the exchange of $\mathrm{Na}^{+}$ions by $\mathrm{K}^{+}$ions, and by a $\mathrm{Ca}\left(\mathrm{NO}_{3}\right)_{2}$ solution to investigate the exchange of $\mathrm{K}^{+}$ions by $1 / 2 \mathrm{Ca}^{2+}$ ions as shown in Table 2 . The investigated concentration ranges covered the concentration variations occurring during hydration in the interstitial solution of cementIERs forms.

Table 2. Experiments performed to measure swelling pressures induced by resins.

\begin{tabular}{|c|c|c|}
\hline Test number & Ionic form of IER in the cell & Percolated solutions \\
\hline I & $\mathrm{Na}^{+}$ & Water $-\mathrm{NaNO}_{3}($ Concentration $: 0 \rightarrow 3 \mathrm{~mol} / \mathrm{L})$ \\
\hline II & $\mathrm{K}^{+}$ & Water $-\mathrm{KNO}_{3}($ Concentration $: 0 \rightarrow 3 \mathrm{~mol} / \mathrm{L})$ \\
\hline III & $\mathrm{Ca}^{2+}$ & Water $-\mathrm{Ca}\left(\mathrm{NO}_{3}\right)_{2}($ Concentration $: 0 \rightarrow 3 \mathrm{~mol} / \mathrm{L})$ \\
\hline IV & $\mathrm{Na}^{+} \rightarrow \mathrm{K}^{+} \rightarrow \mathrm{Ca}^{2+}$ & $\begin{array}{c}\text { Water }-\mathrm{NaNO}_{3}(\text { Concentration: } 0 \rightarrow 3 \text { mol } / \mathrm{L})-\mathrm{KNO}_{3}(\mathrm{Concentration}: 1.4 \\
\rightarrow 0 \mathrm{~mol} / \mathrm{L})- \text { water }-\mathrm{Ca}\left(\mathrm{NO}_{3}\right)_{2}(\text { Concentration }: 2.3 \rightarrow 0 \text { mol/L) - water. }\end{array}$ \\
\hline
\end{tabular}

\subsection{Characterisation of early age hydration}

\subsubsection{Preparation of cement pastes}

Experiments were carried out on (i) cationic resins embedded in cement pastes and, (ii) a reference system consisting of pure hydrated cement. The mix of cement and resins was prepared with commercial IERs (Table 1) in $\mathrm{Na}^{+}, \mathrm{Ca}^{2+}$ and $\mathrm{K}^{+}$ionic form, according to the formula summarized in Table 3. Mixing was performed in two steps: IERs and water were first stirred during $30 \mathrm{~s}$ at low speed in a standardized laboratory mixer (European Standard EN 196-1). Then, cement (CEM I or CEMIII/C) was introduced in the mixer, mixed at low speed for $30 \mathrm{~s}$ and at high speed for 3 min. The high water content enabled to get workable grouts.

Table 3. Encapsulation formula used in this study (wt\%)

\begin{tabular}{|c|c|c|c|}
\hline Component & Density & Percent by weight & Percent by volume \\
\hline CEM III/C / CEM I & $2.91 / 3.09$ & $49.4 \% / 52.5 \%$ & $17.0 \%$ \\
\hline Water & 1 & $39.6 \%$ & $39.6 \%$ \\
\hline$*$ Dry resins (in ionic form $\mathrm{Na}^{+}, \mathrm{K}^{+}$, or $^{2} \mathrm{Ca}^{2+}$ ) & 1.09 & $11.0 \%$ & $10.1 \%$ \\
\hline
\end{tabular}

* In the mixing, the IERs used contained $\sim 50 \mathrm{wt} \%$ of water. The quantity of water added is adjusted to have a water to cement total ratio of 0.8 (this ratio includes the water retained in the IERs)

The fresh grout was cast into 26 hermetically sealed $50 \mathrm{~mL}$ polypropylene containers and stored in a climatic chamber at $20^{\circ} \mathrm{C}$ with $95 \%$ relative humidity.

Experiments were also conducted on pure cement pastes, consisting of CEMIII/C and CEM I cements with an effective water to cement ratio equal to 0.55 . This effective $\mathrm{w} / \mathrm{c}$ ratio was calculated by correcting the total amount of water from that brought by the IERs, which was assessed by measuring their dry extract before the experiment. The pastes exhibited transient bleeding which disappeared after setting. 


\subsubsection{Characterization methods}

Hydration of the pastes was followed using isothermal microcalorimetry at $25^{\circ} \mathrm{C}$ (SETARAM, C80 type). The Vicat setting time was measured according to standard procedure EN 196-3. Hydration was stopped after fixed periods of time (from 1 hour to 10 days) by successively immersing the crushed pastes into isopropanol and drying them in a controlled humidity chamber (with $20 \%$ relative humidity at $22 \pm 2{ }^{\circ} \mathrm{C}$ ). After grinding to a particle size below $80 \mu \mathrm{m}$, the mineralogy of the cement pastes was characterized by X-ray diffraction (Siemens D8, copper anode, $\lambda_{\mathrm{K} \alpha 1}=1.54056 \AA$ Á, $40 \mathrm{~mA}$ and $40 \mathrm{kV}$, scanning from $2 \theta=5^{\circ}$ to $60^{\circ}$ in $0.017^{\circ}$ steps, $50 \mathrm{~s}$ measurement time per step). A semi-quantitative analysis was performed to assess the evolution of the amounts of reactants and products with time. This method consisted in introducing an internal standard (10 $\mathrm{wt} \%$ silicon) into the sample to be analyzed by XRD, and then in calculating the ratio between the area of the most intense diffraction peak of the phase to quantify and that of silicon. The EVA analysis software was used to measure areas of peaks (C 2005 Bruker AXS). The microstructure evolution was observed by Scanning Electron Microscopy on sample fractures at different ages.

The pore solutions of cement pastes were extracted using pressure from 1 hour to 10 days. The $\mathrm{Na}^{+}, \mathrm{K}^{+}, \mathrm{Ca}^{2+}$, and $\mathrm{SO}_{4}{ }^{2-}$ concentrations were measured using ionic chromatography (Dionex DX500 equipped with IonPac CS12A analytical column and IonPac CG12A guard column, injection volume $=25 \mu \mathrm{L}$, eluent $=$ methanesulfonic acid $18 \mathrm{mmol} / \mathrm{L}$, flow rate $=1 \mathrm{~mL} / \mathrm{min}$, detection $=$ suppressed conductivity CSRS 300 suppressor in the autosuppression recycle mode). The hydroxide concentration was calculated assuming electro-neutrality of the solution. The ionic strength was assessed from these concentrations using the CHESS software [15].

\section{Results and discussion}

\subsection{Swelling pressure induced by resins}

\subsubsection{Influence of external solution ionic strength}

Figure 2-a shows the variation of pressure induced by percolation of $\mathrm{NaNO}_{3}$ through the resins in the $\mathrm{Na}^{+}$ionic form. The pressure decreased and rapidly reached equilibrium (within a few tens of minutes) when the concentration of $\mathrm{NaNO}_{3}$ increased, i.e. the resin grains shrunk when the concentration of the external solution increased. Complementary experiments (not shown here) showed the absence of hysteresis: the concentration and duration used in one period did not influence the subsequent period. The resin contraction could be explained assuming that water tended to get out of the resin to reduce the external concentration and equilibrate the chemical potentials. The difference in concentration between the internal solution of IERs and the external solution was thus a key parameter to control the contraction or expansion of the resin grains. As shown by Matsuda et al.[11], the system reached equilibrium when the mechanical pressure induced by the contraction or swelling was equal to the osmotic pressure resulting from the differences in concentration. Figure 2-b summarizes the results of the tests performed on the three ionic forms of the resins: $\mathrm{Na}^{+}, \mathrm{K}^{+}$and $\mathrm{Ca}^{2+}$ (Table 3). Two points may be highlighted. First, when pressure was drawn as a function of activity, the three curves followed the same trend: the pressure decreased when the activity of the percolated solution increased. Then, the curves seemed to tend to an asymptote which might correspond to the limit of water transfer. Second, when pressure was drawn as a function of ionic strength, the curves had not the same behaviour anymore: the ionic strength seemed to have a stronger influence on the IERs saturated with monovalent cations $\left(\mathrm{Na}^{+}, \mathrm{K}^{+}\right)$than with divalent $\mathrm{Ca}^{2+}$. The ionic strength was calculated from the concentrations of the ions in solution. It neglected the internal ionic interactions which depended on the nature of the ions and reduced their reactivity in concentrated medium. On the contrary, to take into account the non ideal behaviour of the solution, the solution activity was calculated from the effective concentrations of the species: the 
actual concentrations were multiplied by the activity coefficients of the corresponding species [16, 17] to take into account the influence of the surroundings which were more important for divalent cations than for monovalent cations.

These results indicated that in a cement-based material, the change in the ionic strength of the interstitial solution with ongoing hydration may induce volume changes in the resins grains, all the more important as the resins are saturated with $\mathrm{Na}^{+}$or $\mathrm{K}^{+}$cations.

a) IER in the $\mathrm{Na}^{+}$form (test I)

b) IER in the $\mathrm{Na}^{+}, \mathrm{K}^{+}$and $\mathrm{Ca}^{2+}$ form

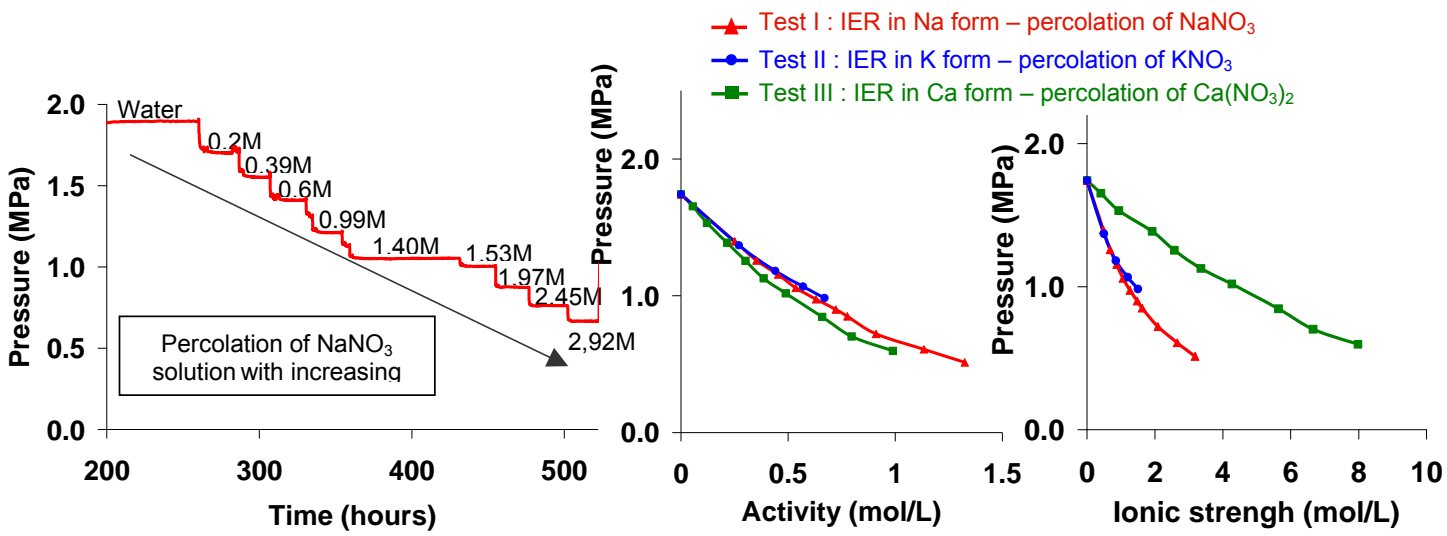

Fig. 2. a) Variation of pressure induced by percolation of $\mathrm{NaNO}_{3}$ solutions through $\mathrm{Na}^{+}$-IERs (Test I) b) Pressure as a function of activity or ionic strength, for IERs in the $\mathrm{Na}^{+}, \mathrm{K}^{+}$or $\mathrm{Ca}^{2+}$ forms (Tests I, II, III)

\subsubsection{Influence of the ionic form of the IERS}

Figure 3 presents the pressure evolution when IERs in the $\mathrm{Na}^{+}$form were successively converted to the $\mathrm{K}^{+}$and $\mathrm{Ca}^{2+}$ forms. Comparing the results achieved with pure water showed that the pressure increased in the following order: $\mathrm{Na}^{+}>>\mathrm{Ca}^{2+}>\mathrm{K}^{+}$. It should be noted that sodium ions have a higher ionic solvated ionic radius $(\sim 4 \AA \hat{)})$ than potassium $(\sim 3.2 \AA \hat{)}$ [ [18]. As for calcium, its solvated ionic radius is close to that of $\mathrm{Na}^{+}$, but since it is a divalent cation, its concentration in the resin is reduced by a factor 2 . Thus, at constant valency, the higher the solvation of the ions fixed by resins, the higher the pressure.

A second cause of IERs expansion in a cement paste would thus be ionic exchange: between $\mathrm{Ca}^{2+}$ ions fixed by the resins and $\mathrm{Na}^{+}$from the solution, or between $\mathrm{K}^{+}$ions fixed by the resins and $\mathrm{Ca}^{2+}$ or $\mathrm{Na}^{+}$from the solution. The strongest swelling would result from the $\mathrm{Ca}^{2+} / \mathrm{Na}^{+}$and $\mathrm{K}^{+} / \mathrm{Na}^{+}$ exchanges. 


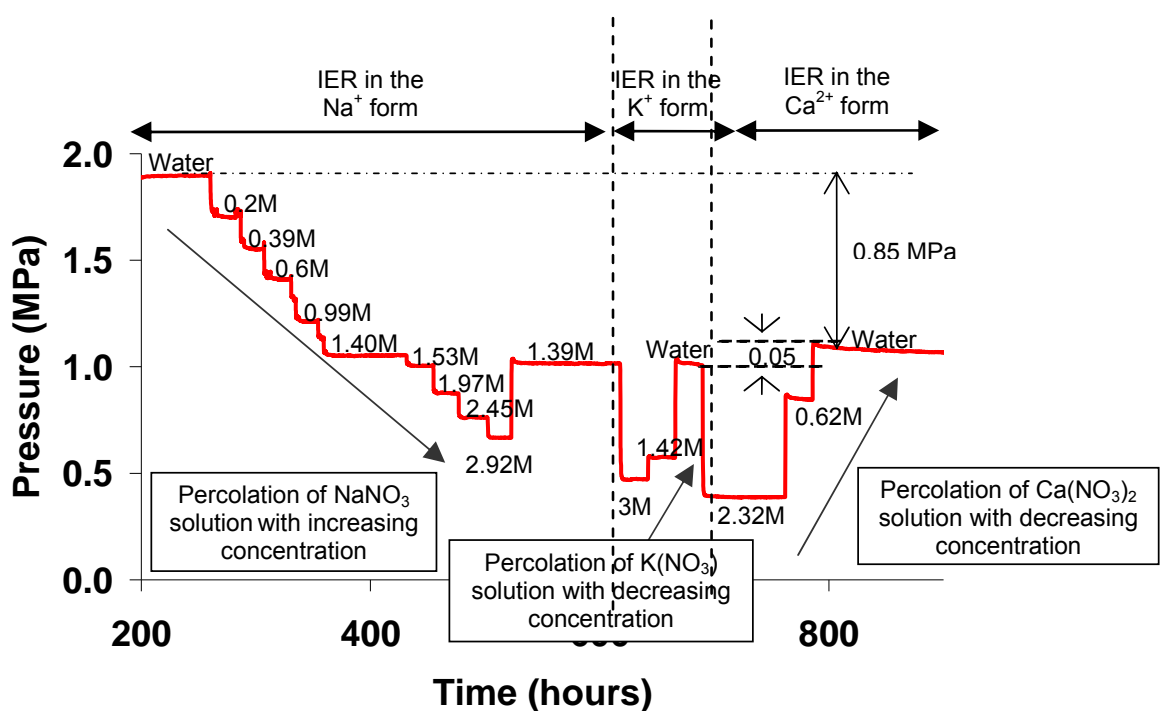

Fig. 3. Influence of the ion nature $\left(\mathrm{Na}^{+}, \mathrm{K}^{+}\right.$, and $\left.\mathrm{Ca}^{2+}\right)$ bound to the resin on swelling pressure (Test IV).

\subsection{Characterisation of early age hydration}

\subsubsection{Vicat setting time}

The Vicat setting time was measured for CEM I and CEM III cement pastes with or without IERs in $\mathrm{Na}^{+}$form. The results are presented in Table 4. The presence of IERs tended to accelerate the setting of both cements. This was consistent with the observations of Morin et al. [7], as reported in section 1. The setting of the CEM III samples remained however much slower than that of the CEM I samples because of the low reactivity of blastfurnace slag [19-21].

Table 4. Vicat setting time (in hours)

\begin{tabular}{|c|c|c|}
\hline $\begin{array}{c}\text { Composition of cement } \\
\text { pastes }\end{array}$ & $\begin{array}{c}\text { Beginning of Vicat } \\
\text { setting time (hours) }\end{array}$ & $\begin{array}{c}\text { End of Vicat setting } \\
\text { time (hours) }\end{array}$ \\
\hline CEM I + $\mathrm{Na}^{+}$-IERs & 3.5 & 8.5 \\
\hline CEM I without IERs & 4 & 11.25 \\
\hline CEM III $+\mathrm{Na}^{+}$-IERs & 6 & 28.5 \\
\hline CEM III without IERs & 6.5 & 30 \\
\hline
\end{tabular}

\subsubsection{Evolution of the pore solution composition at early age}

Figure 4 compares the evolution of the pore solution composition (from $1 \mathrm{~h}$ to $10 \mathrm{~d}$ ), for CEM I and CEM III cement pastes with IERs in $\mathrm{Na}^{+}$form.

In both cement pastes, the sodium concentration rapidly increased during the first $8 \mathrm{~h}$ and reached a maximum which corresponded to about $1 / 3$ of the sodium initially fixed by the resins (35\% for OPC, $30 \%$ for CEM III). This indicated a partial exchange with $\mathrm{Ca}^{2+}$ ions released by the dissolution of the cement anhydrous phases. In the same time, the sulphate concentration increased due to the dissolution of gypsum. From the study performed on IERs only and previously described 
in section 3.1, it was inferred that the $\mathrm{Na}^{+} \leftrightarrow \mathrm{Ca}^{2+}$ exchange as well as the increase in the ionic strength should cause shrinkage of the IERs during this period.

Then, a second stage occurred. Sulphate ions were depleted from the interstitial solution due to the precipitation of ettringite (the exhaustion of gypsum was also observed by XRD at the same time). Besides, the sodium concentration in solution decreased. Since no sodium-bearing hydrate could be detected, a second exchange was assumed: $\mathrm{Ca}^{2+}$ ions were released by the resins to precipitate as cement hydrates (cf. Figure 5-a), whereas $\mathrm{Na}^{+}$ions previously released in the pore solution were fixed by the resins. Both processes should result in a swelling of the resins.

The CEM I and CEM III materials differed by their consolidation rate. For the CEM III matrix, expansion occurred between the beginning and the end of Vicat setting, when the material was still plastic. The CEM I cement exhibited a higher rate of hydration, and swelling of the IERs occurred a few hours after the Vicat end of setting, in a hardened matrix, but with low mechanical strength. The swelling pressure (a few tenths of $\mathrm{MPa}$ ) might have been high enough to induce cracking of the matrix.
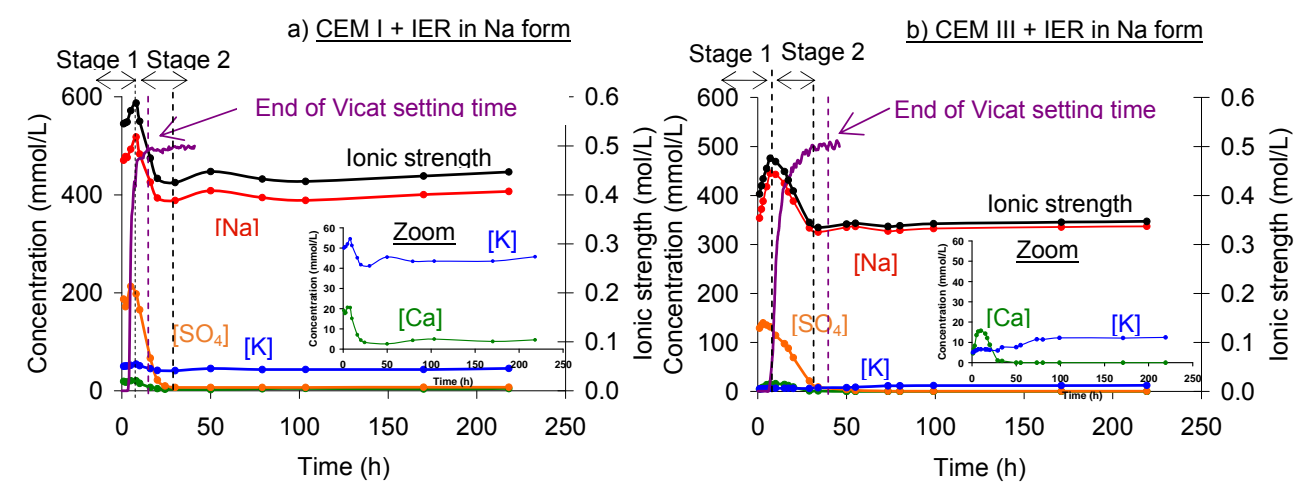

Fig. 4. Evolution of interstitial solution composition $\left(\mathrm{Na}^{+}, \mathrm{K}^{+}, \mathrm{Ca}^{2+}, \mathrm{SO}_{4}{ }^{2-}\right)$ and of the ionic strength for the $\mathrm{CEM} \mathrm{I}+\mathrm{Na}^{+}$-IER (a) and CEM III + $\mathrm{Na}^{+}$-IER samples (b) (the violet curve plots the recording of an automatic Vicat needle unit to determine the initial and final setting of cement).

\subsubsection{Evolution of the mineralogy and the microstructure at early age}

The mineralogy of the pastes prepared with CEM I or CEM III cement and with or without IERs in the $\mathrm{Na}^{+}$form was characterized by XRD. For a given cement, the presence of IERs did not change the phase assemblage. The CEM I-based materials comprised C-S-H, portlandite, ettringite as well as residual anhydrous cement phases. In the CEM III based materials, the main hydrates were C-S-H and ettringite, whereas portlandite could not be detected.

SEM observations on 5d-samples confirmed the precipitation of portlandite in the CEM I cement pastes, as big crystals of few $100 \mu \mathrm{m}$ (Figure 5-a), at the interface between IERs grains and the cement paste. This localized precipitation seemed consistent with the postulated swelling mechanism described in section 3.2.2. The IERs shrinkage in the first stage would create voids at the resins/paste interface. The $\mathrm{Ca}^{2+} / \mathrm{Na}^{+}$exchange in stage 2 would release $\mathrm{Ca}^{2+}$ ions in the highly alkaline pore solution and portlandite would rapidly precipitate at the vicinity of the IERs grains. The possible role of these big portlandite crystals in the expansion process is still unclear. By contrast, in the CEM III samples, the IERs were covered by $\mathrm{C}-\mathrm{S}-\mathrm{H}$ and no localized portlandite precipitation was observed (Figure 5-b). 
a)

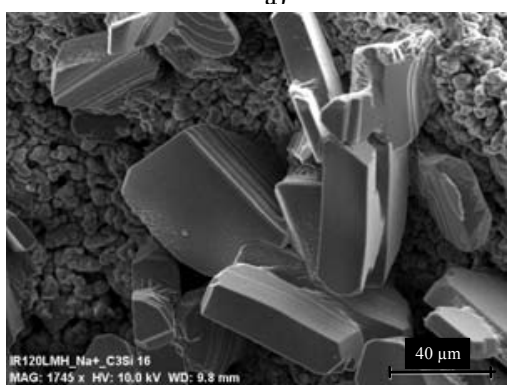

b)

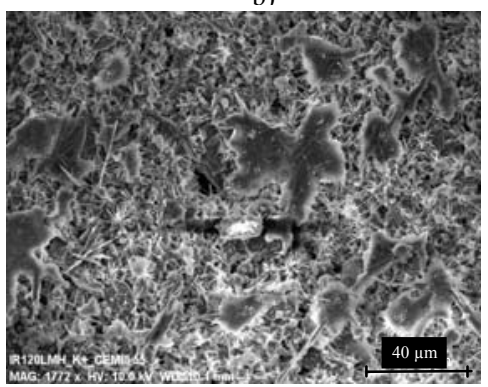

Fig. 5. Observation of resin-cement paste interface by SEM a) CEM I $+\mathrm{Na}^{+}$-IER b) CEM III $+\mathrm{Na}^{+}$-IER

\section{Conclusion}

Cement-based materials are extensively used to encapsulate spent ion exchange resins in the nuclear industry. Cements containing high amounts of blast furnace slag are often preferred to Portland cement because of the enhanced volume stability of the solidified waste forms. The aim of this study was to identify the mechanisms responsible for the volume change of cement pastes containing IERs at early age. The main results can be summarized as follows:

1) The volume change of IERs is strongly influenced by two parameters: the ionic strength of the external solution and the nature of the ions fixed on functional groups. The resins tend to swell if the ionic strength decreases and/or if the ions fixed on their functional group are highly solvated.

2) Two stages are observed during the hydration of CEM I and CEM III incorporating $\mathrm{Na}^{+}-$ IERs: in the first one, a partial $\mathrm{Na}^{+} \leftrightarrow \mathrm{Ca}^{2+}$ exchange occurs in the IERs, as well as an increase in the ionic strength of the pore solution. This should result in shrinkage of the resin grains. In the second one, a reserve $\mathrm{Ca}^{2+} \leftrightarrow \mathrm{Na}^{+}$exchange is observed, as well as a decrease in the ionic strength, which should lead to swelling of the resin grains.

3) In a CEM I matrix, the second stage occurs just after setting, once the material is hard but still poorly consolidated and the swelling pressure of the IERs might be high enough to cause cracking. On the contrary, the CEM III samples exhibit a slower rate of hydration and the second stage occurs before the setting, when the materials can still accommodate deformations.

Future work will aim at measuring the swelling pressures of IERs embedded in cement, and at characterizing the microstructure of cement pastes containing IERs.

\section{References}

[1] Atkins, M. and Glasser, F. P. Application of portland cement-based materials to radioactive waste immobilization. Waste Management, 12, 2-3, (1992), 105-131.

[2] Improved cement solidification of low and intermediate level radioactive waste. AIEA Technical Report Series No. 350, (1993).

[3] Ipatti, A. Solidification of ion-exchange resins with alkali-activated blast-furnace slag. Cement and Concrete Research, 22, 2-3, (1992), 281-286.

[4] Panciatici, G., Belfiore, A. and Poggianti, M. Incorporation of spent ion exchange resins in cement with and without additives. Applied Radiation and Isotopes, 45, 3, (1994), 393-394.

[5] Li, J. and Wang, J. Advances in cement solidification technology for waste radioactive ion exchange resins: A review. Journal of Hazardous Materials, 135, 1-3, (2006), 443-448.

[6] Veazey, G. W. and Ames, R. L. Cement waste-form development for ion-exchange resins at the Rocky Flats Plant. LA--13226-MS; Other: ON: DE97005285; TRN: TRN: 97:002710, (1997). 
[7] Morin, V., Garrault, S., Begarin, F. and Dubois-Brugger, I. The influence of an ion-exchange resin on the kinetics of hydration of tricalcium silicate. Cement and Concrete Research, 40, 10, (2010), 1459-1464.

[8] Sun, Q., Li, J. and Wang, J. Solidification of borate radioactive resins using sulfoaluminate cement blending with zeolite. Nuclear Engineering and Design, 241, 12, (2011), 5308-5315.

[9] Lebescop, P., Bouniol, P. and Jorda, M. Immobilization in cement of ion-exchange resins. Materials Research Soc, Pittsburgh, (1990).

[10] Tremillon, B. Les séparations par les résines échangeuses d'ion, (1965).

[11] Matsuda, M., Nishi, T., Chino, K. and Kikuchi, M. Solidification of Spent Ion-Exchange Resin Using New Cementitious Material .1. Swelling Pressure of Ion-Exchange Resin. Journal of Nuclear Science and Technology, 29, 9, (1992), 883-889.

[12] Matsuda, M., Kikuchi, M. and Takashi, N. Conditioning of Spent Ion Exchange Resin Using High Performance Cement, (1993).

[13] Kikuchi, M., Matsuda, M., Nishi, T., Tsuchiya, H. and Izumida, T. Advanced solidification system using high performance cement. Proceedings of the Fifth International Conference on Radioactive Waste Management and Environmental Remediation. ICEM '95, 2, (1995), 1095-1098.

[14] Epimakhov, V. N. and Oleinik, M. S. Inclusion of radioactive ion-exchange resins in inorganic binders. Atomic Energy, 99, 3, (2005), 607-611.

[15] Van Der Lee, J. Thermodynamic and mathematical conceps of CHESS. Technical Report LHM/RD/98/39, (1998).

[16] Robinson, R. A. The Activity Coefficient of Calcium Nitrate in Aqueous Solution at $25^{\circ}$ from Isopiestic Vapor Pressure Measurements. Journal of the American Chemical Society, 62, 11 1940/11/01, (1940), 3130-3131.

[17] MarcosArroyo, M. D. M., Khoshkbarchi, M. K. and Vera, J. H. Activity coefficients of sodium, potassium, and nitrate ions in aqueous solutions of NaNO3, KNO3, and $\mathrm{NaNO} 3+\mathrm{KNO} 3$ at 25 degrees C. Journal of Solution Chemistry, 25, 10, (1996), 983-1000.

[18] Riemann, W. and Walton, H. F. Ion Exchange in Analytical Chemistry, Oxford, UK, (1970).

[19] Nkinamubanzi, P. C. and Aitcin, P. The use of slag in cement and concrete in a sustainable development perspective. In Proceedings of the ATILH $n^{\circ} 40205$, (2000).

[20] Kolani, B., Buffo-Lacarrière, L., Sellier, A., Escadeillas, G., Boutillon, L. and Linger, L. Hydration of slag-blended cements. Cement and Concrete Composites, 34, 9, (2012), 1009-1018.

[21] Wang, X.-Y., Lee, H.-S., Park, K.-B., Kim, J.-J. and Golden, J. S. A multi-phase kinetic model to simulate hydration of slag-cement blends. Cement and Concrete Composites, 32, 6, (2010), 468477. 